Special issue of the 3rd International Conference on Computational and Experimental Science and Engineering (ICCESEN 2016)

\title{
A Modal Study on the Estimation of Daily Global Solar Radiation from Sunshine Duration
}

\author{
Z. ER ${ }^{a, *}$, Z. ROUABAH ${ }^{b}$ AND I.B. TURNA ${ }^{c}$ \\ ${ }^{a}$ Istanbul Technical University, Faculty of Science and Letters, \\ Physics Engineering Department (13b), 34469 Maslak-Istanbul, Turkey \\ ${ }^{b}$ Materials and Electronic Systems Laboratory, University of Bordj Bou Arreridj, Bordj Bou Arreridj, Algeria \\ ${ }^{c}$ Department of Physics Engineering, Faculty of Science and Letters, Istanbul Technical University, Turkey \\ Building solar plants with suitable placement in the correct geographic areas by utilizing information of solar \\ radiation is the starting point of an investment projects of a solar energy facility. In these premises, several solar \\ radiation models have been improved in order to estimate the solar radiation at a given location, all around the \\ world. Complete and accurate solar radiation data at a specific region are quite important for the solar energy \\ related researches. A number of formulas and models have been developed to estimate solar radiation for the \\ locations, where measured values are not available. Thus, several empirical correlations have been developed in \\ the literature. In this study, models such as the Angström equation, which is reviewed in literature, are used to \\ estimate global solar radiation from sunshine duration in Turkey. In addition, the solar radiation models were \\ examined at the identified solar radiation regions. This study investigates either the correctness of the model itself \\ or the correctness of the estimation of global solar radiation, based on a set of statistical parameters such as $\mathrm{R}^{2}$, \\ RMSE, MBE, MABE, MPE and MAPE.
}

DOI: 10.12693/APhysPolA.132.1070

PACS/topics: Daily Average Solar Radiation, Sunshine Duration, Global Solar Radiation Model

\section{Introduction}

Today, sustainable energy is a developing issue in science, economy and politics. However, in the near future it will be the most important subject in every part of the world. Further, the solar energy is one of the significant sustainable sources.

The most important factor for a solar energy facility is the sunlight. If the solar collector does not receive the proper amount of sunlight, then the whole system will not function at its maximum potential. Therefore, it is necessary to measure the amount of sunlight in the area where one wishes to install a solar energy system.

Measurements can be done by simply using a sunlight calculator or some recording devices and sensors. Estimations can be also done using average daily, monthly or yearly solar insolation, numerical calculations of solar radiation, global isoflux contours and satellite cloud-cover data. The methods for calculating the amount of solar energy from meteorological data require various climatological and physical parameters for solar energy systems. Some of the data are measured directly at weather stations. Other parameters are related to commonly measured data and can be derived with the help of a direct or empirical relationship.

Besides, global solar radiation cannot be detected in huge regions. Thus, there has been a large number of numerical methods that estimate this value. This study

*corresponding author; e-mail: erzuh@itu.edu.tr aims to review the literature, regarding solar radiation models for area that encloses Turkey. The other main objective is to analyze the global solar radiation models for Istanbul. Graphical analyses are done for each reviewed model and, to be more concise, the statistical analyses are also done. The numerical results of each model are analysed by such statistical methods as MPE, MAPE, MBE, RMSE and t-stat.

\section{Materials and methods}

The global solar radiation is defined for selected regions, or more specifically stations. In this study, Istanbul is selected in order to examine the reviewed models in the literature and to define the most appropriate correlation that might be used in the similar climatic regions.

First of all, the altitude and latitude of the province are some of the most important values in order to calculate the solar angle. Istanbul has latitude of 41.10 degrees and altitude of 91 meters.

Turkey comprises different solar radiation ranges, because of its geographical location. The solar radiation distribution map of Turkey is shown in Fig. 1. It contains the data of solar radiation level of Istanbul, where it ranges between $1400 \mathrm{~kW} \mathrm{~h} \mathrm{~m}^{-2}$ year $^{-1}$ and $1500 \mathrm{~kW} \mathrm{~h} \mathrm{~m}^{-2}$ year $^{-1}$.

In addition to these numerical values the literature was also reviewed regarding the calculation of the solar radiation in Istanbul. The models selected from the literature, examined not only Istanbul, but also provinces within Turkey. Therefore the evaluation methods have been tested many times to verify their suitability. 


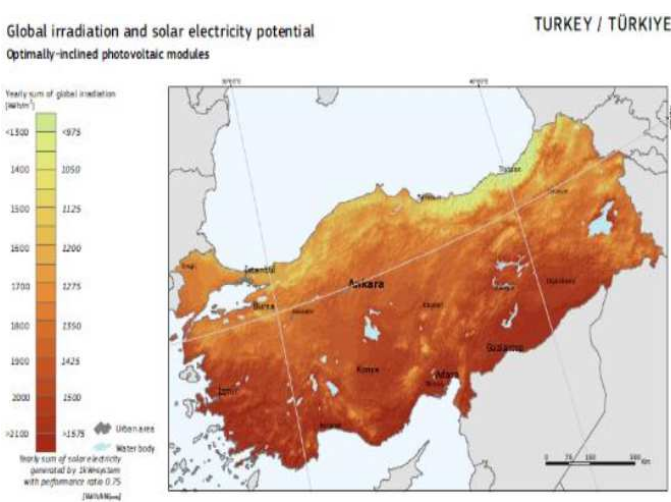

Fig. 1. Solar radiation distribution of Turkey (European Union).

\section{Nomenclature}

$\mathrm{a}, \mathrm{b} \quad$ Coefficients of correlations

$\theta \quad$ Angle of incidence of Sun rays $\left[^{\circ}\right]$

$\theta_{z} \quad$ Solar zenith angle [ $\left.{ }^{\circ}\right]$

$\delta \quad$ Solar declination angle $\left[^{\circ}\right]$

$\phi \quad$ Latitude of the location $\left[{ }^{\circ}\right]$

$w \quad$ The hour angle $\left[^{\circ}\right]$

$w_{s} \quad$ Mean sunrise/sunset hour angle $\left[{ }^{\circ}\right]$

MPE Mean percentage error

MAPE Mean absolute percentage error

MBE Mean bias error $\left[\mathrm{MJ} \mathrm{m}^{-2} \mathrm{~d}^{-2}\right.$ ]

$I_{\mathrm{sc}} \quad$ Solar constant $\left(\sim 1367 \pm 3 \mathrm{~W} / \mathrm{m}^{2}\right)$

$N \quad$ Number of day of year, starting from the first of January

$H \quad$ Monthly average daily global radiation on the horizontal surface [MJ m ${ }^{-2}$ day $^{-1}$ ]

$H_{0} \quad$ Monthly average daily extraterrestrial radiation on the horizontal surface [MJ m${ }^{-2}$ day $^{-1}$ ]

$S \quad$ Monthly average daily hours of bright sunshine [h]

$S_{0} \quad$ Monthly average maximum possible daily sunshine duration [h]

$S / S_{0} \quad$ Relative sunshine duration

RMSE Root mean square error [MJ m ${ }^{-2} \mathrm{~d}^{-2}$ ]

T-Stat t-statistical analysis

Before giving details about the models from literature, the solar angle calculations and solar radiation fundamental equations are given below, in order to show the principles that this study relies on. To begin with, solar angles should be clarified. The declination angle is the most important angle, value of which varies between -23.45 degrees, at winter solstice on December $21^{\text {st }}$, and 23.45 degrees, at summer solstice on June $21^{\text {st }}$, represented by $\delta$.

Another fundamental angle is the hour angle, which is the angle between the longitude where the Sun rays perpendicular and the longitude of the examined point. The angle between the direction of the geometric center of the Sun and the horizontal plane at the considered point is the solar altitude angle, which is also the complement of the solar zenith angle [1-5].

$$
\begin{aligned}
& \delta=23.45^{\circ} \sin \left[\frac{360(284+n)}{365}\right] . \\
& w=15(\text { solar time }-12) . \\
& w_{s}=\cos ^{-1}(-\tan \phi \tan \delta) .
\end{aligned}
$$

In order to determine the solar radiation data, the knowledge of solar angles is not quite enough. Though, there have been numerous methods for estimation of solar radiation, developed in the history of science, the most important one is the correlation, which was proposed by Angstrom, depending on the monthly average clear sky daily total radiation on horizontal surface for a given location $[6,7]$. However, the monthly average clear sky daily total radiation on horizontal surface is difficult to estimate. Therefore, Prescott has modified the Angstrom's method by introducing the dependence on extraterrestrial radiation, instead of clear sky daily radiation, as given in Eq. (4) [8-21].

$$
\frac{H}{H_{0}}=a+b\left(\frac{S}{S_{0}}\right)
$$

where the monthly average daily extraterrestrial radiation on the horizontal surface is formulated with Eq. (5).

$$
\begin{aligned}
& H_{0}=\frac{24}{\pi} I_{\mathrm{sc}}\left[1+0.033 \cos \left(\frac{360 n}{365}\right)\right] \times \\
& {\left[\cos (\phi) \cos (\delta) \sin \left(w_{s}\right)+\frac{\pi}{180} w_{s} \sin (\phi) \sin (\delta)\right] .}
\end{aligned}
$$

The mentioned equation also depends on the relative sunshine duration. The monthly average maximum possible daily sunshine duration can be defined via the mean sunset/sunrise hour angle, as shown in the following equation.

$$
S_{0}=\frac{2}{15} w_{s}
$$

The monthly average maximum possible daily sunshine duration can be also computed using the latitude and the solar declination angle.

$$
S_{0}=\frac{2}{15} \cos ^{-1}(-\tan \phi \tan \delta) .
$$

As the fundamentals are explained above, the models considered in this study are shown in Table I. As can be seen, most of the models depend on relative sunshine duration. The model 1 by Kilic and Ozturk proposes new correlation coefficients for Angstrom equation, which are related to latitude angle, declination angle and solar altitude of the province.

Model 8 has sub model, named $8 \mathrm{~b}$, which depends on declination angle as well. Model 10 has sub models, which are also divided into two groups, according to the months of the year. Finally, model 13a is also based not only on the relative sunshine duration, but also on the latitude of the station. 
TABLE I

Sets of model correlations and constructor(s).

\begin{tabular}{|c|c|c|c|c|}
\hline $\begin{array}{c}\text { Set/ } \\
\text { Model No. }\end{array}$ & $\begin{array}{c}\text { Author } \\
\text { names }\end{array}$ & \multicolumn{3}{|c|}{ Correlation(s) } \\
\hline $\begin{array}{c}\text { Set 1/ } \\
\text { Model } 1\end{array}$ & $\begin{array}{c}\text { Kilic } \\
\text { and Ozturk }\end{array}$ & \multicolumn{3}{|c|}{$\begin{array}{c}a=0.103+0.000017 z+0.198 \cos (\phi-\delta) \\
b=0.533-0.165 \cos (\phi-\delta)\end{array}$} \\
\hline $\begin{array}{c}\text { Set 1/ } \\
\text { Model } 2\end{array}$ & Ogelman et al. & \multicolumn{3}{|c|}{$\frac{H}{H_{0}}=0.195+0.676\left(\frac{S}{S_{0}}\right)-0.142\left(\frac{S}{S_{0}}\right)^{2}$} \\
\hline $\begin{array}{c}\text { Set 1/ } \\
\text { Model } 3\end{array}$ & $\begin{array}{c}\text { Akinoglu } \\
\text { and Ecevit }\end{array}$ & \multicolumn{3}{|c|}{$\frac{H}{H_{0}}=0.145+0.845\left(\frac{S}{S_{0}}\right)-0.280\left(\frac{S}{S_{0}}\right)^{2}$} \\
\hline $\begin{array}{c}\text { Set 1/ } \\
\text { Model } 4\end{array}$ & $\begin{array}{l}\text { Tasdemiroglu } \\
\text { and Sever }\end{array}$ & \multicolumn{3}{|c|}{$\frac{H}{H_{0}}=0.225+0.014\left(\frac{S}{S_{0}}\right)+0.001\left(\frac{S}{S_{0}}\right)^{2}$} \\
\hline $\begin{array}{c}\text { Set } 1 / \\
\text { Model } 5\end{array}$ & $\begin{array}{l}\text { Yildiz } \\
\text { and } \mathrm{Oz}\end{array}$ & \multicolumn{3}{|c|}{$\frac{H}{H_{0}}=0.2038+0.9236\left(\frac{S}{S_{0}}\right)-0.3911\left(\frac{S}{S_{0}}\right)^{2}$} \\
\hline $\begin{array}{c}\text { Set 2/ } \\
\text { Model } 6\end{array}$ & Tiris et al. & \multicolumn{3}{|c|}{$\frac{H}{H_{0}}=0.18+0.62\left(\frac{S}{S_{0}}\right)$} \\
\hline $\begin{array}{c}\text { Set 2/ } \\
\text { Model } 7\end{array}$ & Aksoy & \multicolumn{3}{|c|}{$\frac{H}{H_{0}}=0.148+0.668\left(\frac{S}{S_{0}}\right)-0.079\left(\frac{S}{S_{0}}\right)^{2}$} \\
\hline $\begin{array}{c}\text { Set 2/ } \\
\text { Model } 8\end{array}$ & $\begin{array}{c}\text { Togrul } \\
\text { and Onat }\end{array}$ & $\begin{array}{l}\text { (a) } \\
\text { (b) }\end{array}$ & \multicolumn{2}{|c|}{$\begin{array}{l}\frac{H}{H_{0}}=-1.3876+0.518 H_{0}+2.3064\left(\frac{S}{S_{0}}\right) \\
\frac{H}{H_{0}}=2.765+4.9597 \sin (\delta)+2.2984\left(\frac{S}{S_{0}}\right)\end{array}$} \\
\hline $\begin{array}{c}\text { Set 2/ } \\
\text { Model } 9 \\
\end{array}$ & $\begin{array}{c}\text { Togrul } \\
\text { and Onat }\end{array}$ & \multicolumn{3}{|c|}{$\frac{H}{H_{0}}=-0.21521+0.62487\left(\frac{S}{S_{0}}\right)-0.2205\left(\frac{S}{S_{0}}\right)^{2}$} \\
\hline \multirow[t]{6}{*}{$\begin{array}{c}\text { Set 3/ } \\
\text { Model } 10\end{array}$} & \multirow[t]{6}{*}{ Togrul et al. } & & From October to March; & From April to September; \\
\hline & & (a) & $\begin{array}{l}\frac{H}{H_{0}}=-0.0059 \ln \left(\frac{S}{S_{0}}\right)+0.2255- \\
0.0076 \ln \left(\frac{S}{S_{0}}\right)+0.4556\left(\frac{S}{S_{0}}\right)\end{array}$ & $\begin{array}{l}\frac{H}{H_{0}}=-0.1752 \ln \left(\frac{S}{S_{0}}\right)+0.1474+ \\
0.1486 \ln \left(\frac{S}{S_{0}}\right)+0.5125\left(\frac{S}{S_{0}}\right)\end{array}$ \\
\hline & & (b) & $\frac{H}{H_{0}}=0.2371+0.4358\left(\frac{S}{S_{0}}\right)+0.0188\left(\frac{S}{S_{0}}\right)^{2}$ & $\frac{H}{H_{0}}=0.4037+0.0203\left(\frac{S}{S_{0}}\right)+0.2352\left(\frac{S}{S_{0}}\right)^{2}$ \\
\hline & & (c) & $\begin{array}{l}\frac{H}{H_{0}}=0.276+0.359\left(\frac{S}{S_{0}}\right)-0.366\left(\frac{S}{S_{0}}\right)^{2}+ \\
0.607\left(\frac{S}{S_{0}}\right)^{3}\end{array}$ & $\begin{array}{l}\frac{H}{H_{0}}=-0.068+2.0955\left(\frac{S}{S_{0}}\right)-2.761\left(\frac{S}{S_{0}}\right)^{2}+ \\
1.422\left(\frac{S}{S_{0}}\right)^{3}\end{array}$ \\
\hline & & (d) & $\begin{array}{l}\frac{H}{H_{0}}=0.216+0.914\left(\frac{S}{S_{0}}\right)-1.423\left(\frac{S}{S_{0}}\right)^{2}+ \\
0.382\left(\frac{S}{S_{0}}\right)^{3}+1.065\left(\frac{S}{S_{0}}\right)^{4}\end{array}$ & $\begin{array}{l}\frac{H}{H_{0}}=-0.399+5.333\left(\frac{S}{S_{0}}\right)-12.849\left(\frac{S}{S_{0}}\right)^{2}+ \\
14.088\left(\frac{S}{S_{0}}\right)^{3}-5.569\left(\frac{S}{S_{0}}\right)^{4}\end{array}$ \\
\hline & & (e) & $\begin{array}{l}\frac{H}{H_{0}}=0.163+1.965\left(\frac{S}{S_{0}}\right)-8.837\left(\frac{S}{S_{0}}\right)^{2}+ \\
22.257\left(\frac{S}{S_{0}}\right)^{3}-26.557\left(\frac{S}{S_{0}}\right)^{4}+12.308\left(\frac{S}{S_{0}}\right)^{5}\end{array}$ & $\begin{array}{l}\frac{H}{H_{0}}=5.606-39.687\left(\frac{S}{S_{0}}\right)+120.7408\left(\frac{S}{S_{0}}\right)^{2}- \\
181.821\left(\frac{S}{S_{0}}\right)^{3}+136.762\left(\frac{S}{S_{0}}\right)^{4}-40.974\left(\frac{S}{S_{0}}\right)^{5}\end{array}$ \\
\hline $\begin{array}{l}\text { Set } 4 / \\
\text { Model } 11\end{array}$ & $\begin{array}{l}\text { Ertekin } \\
\text { and Yaldiz }\end{array}$ & \multicolumn{3}{|c|}{$\frac{H}{H_{0}}=-2.4375+11.946\left(\frac{S}{S_{0}}\right)-16.745\left(\frac{S}{S_{0}}\right)^{2}+7.9575\left(\frac{S}{S_{0}}\right)^{3}$} \\
\hline $\begin{array}{c}\text { Set } 4 / \\
\text { Model } 12\end{array}$ & $\begin{array}{l}\text { Ulgen and } \\
\text { Ozbalta }\end{array}$ & \multicolumn{3}{|c|}{$\frac{H}{H_{0}}=0.2424+0.5014\left(\frac{S}{S_{0}}\right)$} \\
\hline $\begin{array}{c}\text { Set } 4 / \\
\text { Model } 13\end{array}$ & $\begin{array}{l}\text { Ulgen and } \\
\text { Hepbasli }\end{array}$ & $\begin{array}{l}\text { (a) } \\
\text { (b) }\end{array}$ & \multicolumn{2}{|c|}{$\begin{array}{c}\frac{H}{H_{0}}=0.3092 \cos (\phi)+0.4931 \frac{S}{S_{0}} \\
\frac{H}{H_{0}}=0.2408+0.3625\left(\frac{S}{S_{0}}\right)+0.4597\left(\frac{S}{S_{0}}\right)^{2}-0.3708\left(\frac{S}{S_{0}}\right)^{3}\end{array}$} \\
\hline $\begin{array}{c}\text { Set } 5 / \\
\text { Model } 14\end{array}$ & $\begin{array}{l}\text { Ulgen and } \\
\text { Hepbasli }\end{array}$ & $\begin{array}{l}\text { (a) } \\
\text { (b) }\end{array}$ & \multicolumn{2}{|c|}{$\begin{array}{c}\frac{H}{H_{0}}=0.2671+0.4754\left(\frac{S}{S_{0}}\right) \\
\frac{H}{H_{0}}=0.2854+0.2591\left(\frac{S}{S_{0}}\right)+0.6171\left(\frac{S}{S_{0}}\right)^{2}-0.4834\left(\frac{S}{S_{0}}\right)^{3}\end{array}$} \\
\hline $\begin{array}{c}\text { Set } 5 / \\
\text { Model } 15\end{array}$ & $\begin{array}{l}\text { Aras, Balli, } \\
\text { Hepbasli }\end{array}$ & $\begin{array}{l}\text { (a) } \\
\text { (b) } \\
\text { (c) }\end{array}$ & \multicolumn{2}{|c|}{$\begin{array}{c}\frac{H}{H_{0}}=0.3078+0.4166\left(\frac{S}{S_{0}}\right) \\
\frac{H}{H_{0}}=0.3398+0.2868\left(\frac{S}{S_{0}}\right)+0.1187\left(\frac{S}{S_{0}}\right)^{2} \\
\frac{H}{H_{0}}=0.4832-0.6161\left(\frac{S}{S_{0}}\right)+1.8932\left(\frac{S}{S_{0}}\right)^{2}-1.0975\left(\frac{S}{S_{0}}\right)^{3}\end{array}$} \\
\hline $\begin{array}{l}\text { Set 6/ } \\
\text { Model } 16\end{array}$ & Tahran, Sari & $\begin{array}{l}\text { (a) } \\
\text { (b) }\end{array}$ & \multicolumn{2}{|c|}{$\begin{array}{c}\frac{H}{H_{0}}=0.1874+0.8592\left(\frac{S}{S_{0}}\right)-0.4764\left(\frac{S}{S_{0}}\right)^{2} \\
\frac{H}{H_{0}}=0.1520+1.1334\left(\frac{S}{S_{0}}\right)-1.1126\left(\frac{S}{S_{0}}\right)^{2}+0.4516\left(\frac{S}{S_{0}}\right)^{3}\end{array}$} \\
\hline $\begin{array}{c}\text { Set 6/ } \\
\text { Model } 17\end{array}$ & Bakirci & \multicolumn{3}{|c|}{$\frac{H}{H_{0}}=0.6307-0.7251\left(\frac{S}{S_{0}}\right)+1.2089\left(\frac{S}{S_{0}}\right)^{2}-0.4633\left(\frac{S}{S_{0}}\right)^{3}$} \\
\hline $\begin{array}{c}\text { Set } 6 / \\
\text { Model } 18\end{array}$ & Bakirci & \multicolumn{3}{|c|}{$\frac{H}{H_{0}}=0.2786+0.4160\left(\frac{S}{S_{0}}\right)$} \\
\hline
\end{tabular}

To ensure the appropriate model for Istanbul, statistical analysis methods were used with regard to the measured monthly average global radiation, for each month of the year. These data were obtained from Turkey Meteorology Station. The widely used statistical analysis methods applied in this study are explained below. The devi- ation between measured and calculated monthly average daily global solar radiation is named after the relative percentage error $e$, which is commonly used in analysis.

$$
e=\left(\frac{c_{i}-m_{i}}{m_{i}}\right) \times 100 .
$$


Here $c_{i}$ is the calculated value and $m_{i}$ is the measured value. In this study, $m_{i}$ represents the data obtained from the Turkey Meteorology Station, while $c_{i}$ is obtained from the evaluated models. The ideal result for relative percentage error is equal to zero.

The mean percentage error (MPE) is the other statistical analysis method reviewed in this study. This method also includes the relative percentage error within calculations, as presented below, where the number of data pairs is shown as $n$.

$$
\mathrm{MPE}=\frac{1}{n} \sum_{i=1}^{n} e .
$$

The mean absolute percentage error (MAPE) is the absolute value of MPE, as can be understood from the name. It can also be defined as the absolute average of the relative percentage error. The formula for the mean absolute percentage error is given as

$$
\text { MAPE }=\frac{1}{n} \sum_{i=1}^{n}|e| .
$$

The other commonly used statistical analysis method is the mean bias error (MBE). This method gives information about the accuracy and performance for the long term period.

$$
\mathrm{MBE}=\frac{1}{n} \sum_{i=1}^{n}\left(c_{i}-m_{i}\right) .
$$

As stated above, $c_{i}$ is the calculated value and $m_{i}$ is the measured value. The ideal value for MBE is also zero. Similarly, root mean square error (RMSE) depends not on the relative percentage error, but on the calculated and measured values only. RMSE gives always positive values or zero.

$$
\mathrm{RMSE}=\sqrt{\frac{1}{n} \sum_{i=1}^{n}\left(c_{i}-m_{i}\right)^{2}} .
$$

At last, the t-statistical analysis method was also considered to be applied to the reviewed models. This analysis method includes both mean bias error and root mean square error as formalized below.

$$
\text { t-stat }=\sqrt{\frac{(n-1) \mathrm{MBE}^{2}}{\mathrm{RMSE}^{2}-\mathrm{MBE}^{2}}} .
$$

The performance of the considered model can be seen by investigating the t-stat value. Smaller t-stat value shows better performance of the model, which explains why the ideal value is zero. The evaluation of the reviewed models is not the appropriate way of defining the method applicable for Istanbul or any other station. The statistical analysis methods should be used in order to get reliable results. Accordingly, the models are examined both numerically and statistically in this study.

\section{Results and discussion}

The first set of models demonstrates that the worst and the best results were obtained with the Model 4 by Taşdemiroglu and Sever and Model 5 by Yildiz and $\mathrm{Oz}$, respectively. On the other hand, Model 1 by Kilic and Ozturk shows the most appropriate result, as it has the nearest values to the measured monthly average daily global radiation. According to numerical results, the statistical results also show that Model 1 has the most relevant results compared to the rest of the models of the first set.

The evaluation of the second set for Istanbul shows negative results for Model 9 by Toğrul and Onat, as it is expected. To be more clear, the proposed correlation is for the station Elazig, which is within the fourth region of the range of solar radiation distribution in Turkey and is the completely different range from the evaluated station. Therefore, the results of statistical analysis verify the distribution.

Other models show positive results. In the first and last quarter of the year Model 8a shows the highest results with different correlation type, where Model 7 has the nearest values to the measured data. Further, the rest of the year Model 6, with the linear equation, has represented the highest values, where Model 8a has more appropriate results. Overall, the performance of the Model 7 is better than the other results.

Model 10 by Togrul et al. is investigated within the third set. Although there have been fluctuations between the sub-models, they all show results similar with the measured data, except Model 10b, between August and the end of the year. However, according to the statistical results Model 10b has shown the smallest t-statistical results.

On the other hand, Model 10c shows better short term and long term performances according to the root mean square and mean bias error, respectively. These results are expected, because of the correlation type of the Model 10, in general.

The fourth set of models has negative results, like the second set of models. Model 11 by Ertekin and Yildiz has negative results, as it is proposed for the station from the fourth region of solar radiation distribution range of Turkey. Besides, the other models of fourth set have values close to each other, and to the measured values.

In order to define the most applicable model, the statistical analysis methods show that Model 13a is the most appropriate model among other models of the fourth set, for Istanbul.

Model 14 by Ulgen and Hepbasli and Model 15 by Aras, Balli and Hepbasli are examined within the fifth set of models for Istanbul. Although the numerical results are almost equal, Model 14a is more applicable, compared to the sub-models of Model 15. Further, the statistical results, with the exception of t-statistical analysis, confirm the numerical conclusions. While results state that Model 14a has the best short term and long term performance, Model 15c has the best performance in general.

At last, the sixth set of models shows that Models 16a and $16 \mathrm{~b}$ show almost equal results through the entire year. Besides, until the end of May Model 18 has the nearest values to the measured data. By the end of the 
year Model 17 has higher values compared to the rest. As the results of statistical analysis show, Model 18 is more applicable while Model 16a has lower t-statistical result.

The comparison of all models according to statistical analysis methods states that there have been three models that are more applicable for Istanbul than others. According to to the mean percentage and mean absolute percentage error, Model 1 has the nearest result to the ideal value. Further, the mean bias error and root mean square error, which give information about the accuracy and performance for long and short term period, respectively, show that Model 10c has the lowest values. Meanwhile, Model 16a shows better performance according to the t-statistical result, which is 0.42 . Figure 2 shows the results, which were described above.
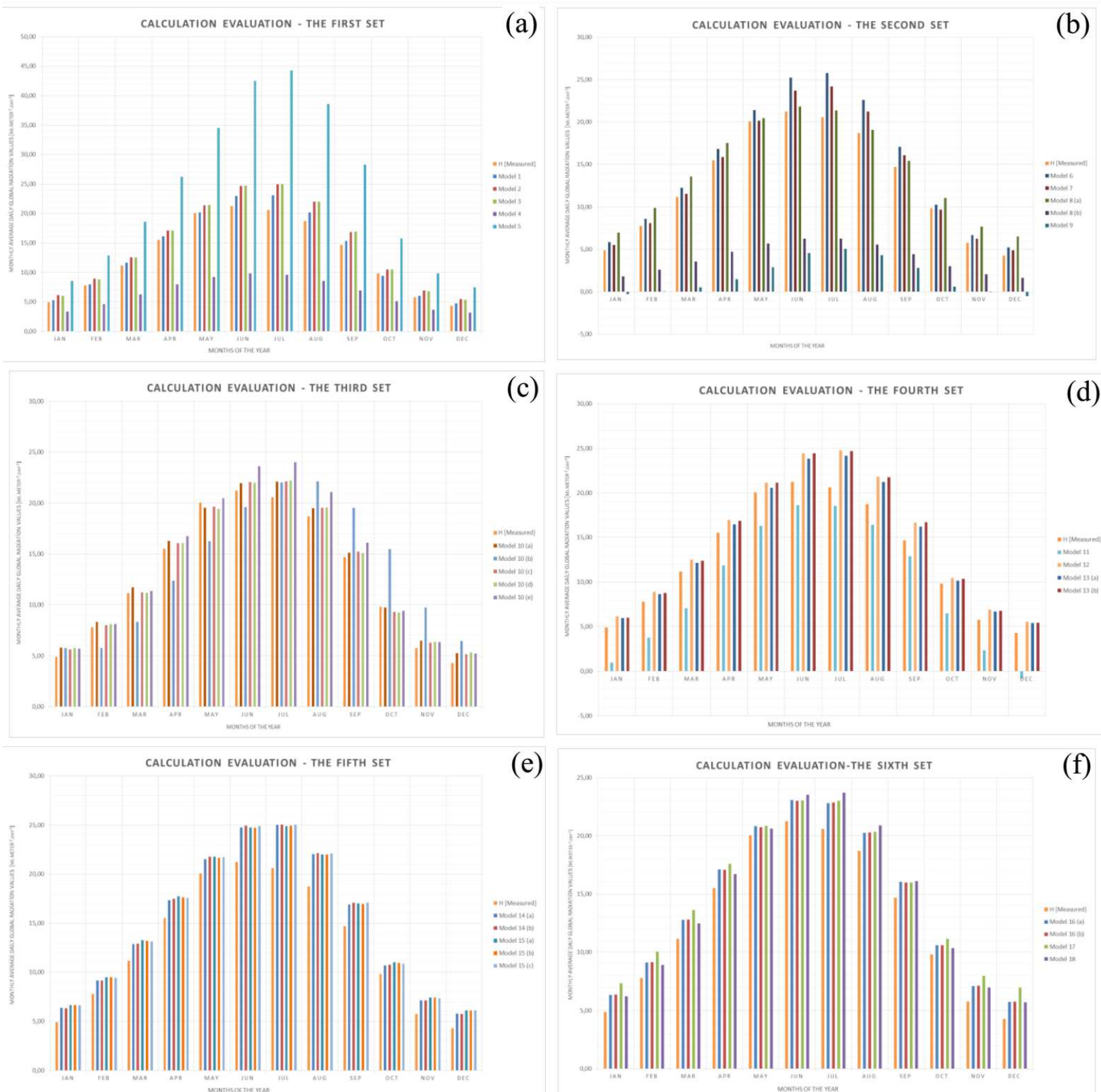

(e)
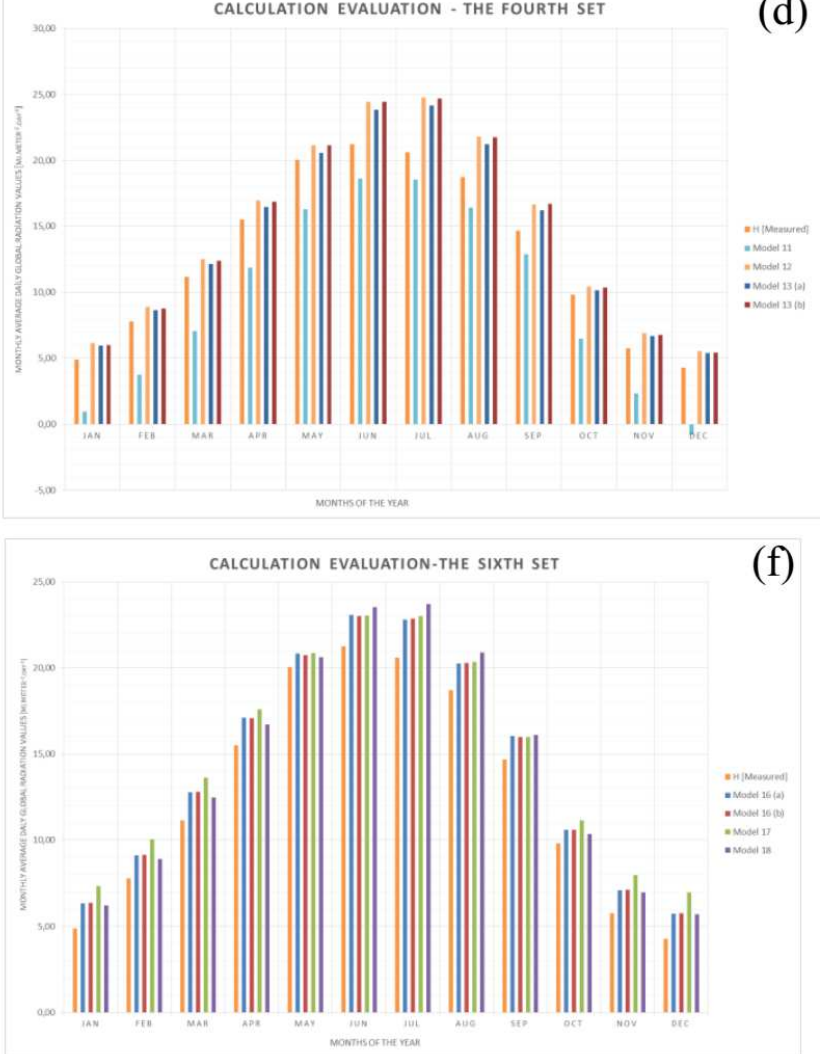

Fig. 2. Evaluation of correlations for six sets of models with the experimental data for Istanbul.

\section{Conclusions}

The monthly average global solar radiation and the monthly average maximum possible daily sunshine duration in Istanbul are analyzed in this work. Several models have been found in the literature for the estimation of the global solar radiation. Some of them were selected and applied to predict monthly average daily global solar radiation on a horizontal surface in Istanbul. The agreement between the calculated and estimated values is remarkable and these models are recommended for use in any location in Turkey or for stations with a similar climate. 


\section{References}

[1] N.C. Bezir, I. Akkurt, N. Ozek, Energy Sourc. Part A: Recovery, Utilization, Environ. Eff. 32512 (2010).

[2] Y. Miyake, Int. J. Solar Ener. 9, 47 (1990).

[3] N.C. Bezir, I. Akkurt, N. Ozek, Energy Sourc. Part A: Recovery, Utilization, Environ. Eff. 32, 995 (2010).

[4] Z. Er, Acta Phys. Pol. A 128, B-300 (2015).

[5] M. Boaro, D. Fuselli, F. De Angelis, D. Liu, Q. Wei, F. Piazza, Cong. Comput. 5, 264 (2013).

[6] A. Angström, Quart. J. Royal Meteorolog. Soc. 50, 121 (1924).

[7] A. Kılıc, A. Ozturk, Günes Enerjisi, Kipas Dagitim, Istanbul 1983.

[8] H. Ogelman, A. Ecevit, E. Tasdemiroglu, Solar Energy 33, 619 (1984).

[9] B.G. Akinoglu, A. Ecevit, Solar Energy 15, 865 (1990).

[10] E. Tasdemiroglu, R. Sever, Energy Conv. Manag. 31, 599 (1991).
[11] M. Yildiz, S. Oz, in: Proc. 6th National Energy Congress, 1994, p. 250.

[12] B. Aksoy, Renew. Energy 10, 625 (1997).

[13] I.T. Toğrul, E. Onat, Energy Conv. Manag. 40, 1577 (1999).

[14] H. Aras, O. Balli, A. Hepbasli, Energy Sources Part B 1, 303 (2006).

[15] K. Bakirci, Energy 34, 485 (2009).

[16] M.J. Ahmad, G.N. Tiwari, Int. J. Energy Environ. 1, 513 (2010).

[17] N. Khaliliaqdam, A. Soltani, IJACS 4, 971 (2012).

[18] F. Besharat, A.A. Dehghan, A.R. Faghih, Renew. Sustainable Energy Rev. 21, 798 (2013).

[19] W. Yao, Z. Li, Y. Wang, F. Jiang, L. Hu, Energy Conv. Manag. 84, 597 (2014).

[20] M.A. Kallioğlu, Ph.D. Thesis, Niğde Üniversitesi, 2014.

[21] Z. Er, I.B. Tuna, Acta Phys. Pol. A, 129, 865 (2016). 